\title{
EDUCAÇÃO, CULTURA POPULAR E EDUCAÇÃO DE JOVENS E ADULTOS
}

\author{
Clarice Wilken de Pinho (UFMG)* \\ http://orcid.org/0000-0002-8028-2639 \\ Leôncio Soares (UFMG)** \\ http://orcid.org/0000-0003-4750-2529
}

Fernanda A. O. Rodrigues Silva (UFOP)***

http://orcid.org/0000-0002-8790-0882

\section{RESUMO}

A atenção à riqueza das experiências culturais presentes nas múltiplas identidades dos jovens e adultos é a base dos movimentos de educação e cultura popular que eclodiram no Brasil na década de 1960. Destacam-se os conceitos assumidos, os objetivos e os planos de ação desenvolvidos no interior do Movimento de Cultura Popular (MCP); da Campanha de Pé no Chão Também se Aprende a Ler; do Movimento de Educação de Base (MEB) e do Centro Popular de Cultura (CPC) com o objetivo de delinear a educação e cultura popular em diferentes contextos e sua contribuição para a educação de jovens e adultos. Conclui-se que as contribuições da história, trazidas à luz nas referências da década de 1960, indicam a necessidade de um trabalho de cultura popular assumidamente libertador, não mais pensado como uma cultura para as pessoas, mas com as pessoas, com os sujeitos participantes e construtores de uma sociedade que os represente.

Palavras-chave: Educação de Jovens e Adultos. Educação popular. Cultura popular. Movimentos de educação e cultura popular. Sujeitos.

\section{ABSTRACT}

\section{EDUCATION, POPULAR CULTURE AND YOUNG AND ADULT EDUCATION}

The attention to the richness of cultural experiences present in the multiple identities of young and adults is the basis of education and popular culture movements; which emerged in Brazil in the 1960s. The incorporated concepts, the objectives and the action plans proceeded in the Movimento de Cultura Popular (MCP); the Campanha de Pé no Chão Também se Aprende a Ler; the Movimento de Educação de Base (MEB) and the Centro Popular de Cultura (CPC)

\footnotetext{
* Mestra em Educação pela Universidade Federal de Minas Gerais (UFMG). Professora da Rede Municipal de Educação de Belo Horizonte. E-mail: clarice_fae@yahoo.com.br

** Doutor em Educação pela Universidade de São Paulo (USP). Professor Titular da Universidade Federal de Minas Gerais (UFMG). E-mail: leonciogsoares@gmail.com

*** Doutora em Educação pela Universidade Federal de Minas Gerais (UFMG). Professora da Universidade Federal de Ouro Preto (UFOP). E-mail: anandasilva1979@gmail.com
} 
with the objective to delineate the education and popular culture in different contexts and their contribution to the youth and adults education. This study concluded that the contributions of history, brought to light in the references of the 1960s, indicate the need for an openly liberating popular culture work; no longer thought of as a culture for people, but with people, with the participating subjects and creators of a society that represents them.

Keywords: Young and Adult Education. Popular education. Popular culture. Movement of education and popular culture. Subject.

\section{RESUMEN \\ EDUCACIÓN, CULTURA POPULAR Y EDUCACIÓN DE JÓVENES Y ADULTOS}

La atención dada a la riqueza de las experiencias culturales presentes en las múltiples identidades de jóvenes y adultos es la base de los movimientos de educación y cultura popular que surgieran en Brasil en la década de 1960. Los conceptos asumidos, los objetivos y los planes de acción desarrollados dentro del Movimento de Cultura Popular (MCP); la campaña De Pé no Chão Também se Aprende a Ler; el Movimento de Educação de Base (MEB) y el Centro Popular de Cultura (CPC) con el objetivo de delinear la educación y la cultura popular en diferentes contextos y su contribución a la educación de jóvenes y adultos. Se concluye que las contribuciones de la historia, traídas a la luz de las referencias de la década de 1960, indican la necesidad de un trabajo de la cultura popular que se asume liberador, que ya no se considera como una cultura para las personas, sino con personas, con sujetos participantes y constructores de una sociedad que los representa.

Palabras clave: Educación para Jóvenes y Adultos. Educación popular. Cultura popular. Movimiento de educación y cultura popular. Sujetos.

\section{Introdução}

Você quando anda, anda com a sua cultura. (FREIRE, 2003, p. 341).

Educação Popular ou Cultura Popular, com ou sem estes nomes, foi e continua sendo um trabalho que abrange os sujeitos das classes populares "compreendidos não como beneficiários tardios de um 'serviço', mas como protagonistas emergentes de um 'processo'" (BRANDÃO, 2002a, p. 142, grifo do autor).

0 objetivo deste artigo é construir uma base de conceitos sobre educação e cultura popular. ${ }^{1}$ Para a sua concretização, foi necessária

1 Este artigo tem como base as análises desenvolvidas na dissertação Educação e cultura popular nas propostas escolares de EJA - Educação de Jovens e Adultos: um estudo em duas escolas de Belo Horizonte (PINHO, 2016). A referida uma imersão nos principais movimentos de educação e cultura popular que eclodiram no Brasil na década de 1960, destacando as propostas desenvolvidas no interior de quatro deles: Movimento de Cultura Popular (MCP); Campanha de Pé no Chão Também se Aprende a Ler; Movimento de Educação de Base (MEB) e Centro Popular de Cultura (CPC).

$A$ atenção à riqueza das experiências culturais que formam as múltiplas identidades dos

pesquisa buscou analisar o trabalho educacional e cultural desenvolvido em duas escolas distintas relacionados às expressões da vida de quem é das camadas populares. 0 objetivo foi identificar o envolvimento dos estudantes jovens e adultos em atividades culturais de diversas naturezas, vinculadas aos seus saberes e às suas culturas. 
jovens e adultos da Educação de Jovens e Adultos (EJA) é de fundamental importância para construir um currículo "com" os educandos - e não "para" os educandos. Estabelecer um diálogo entre as necessidades e as demandas educacionais e culturais é um aspecto basilar para desenvolver o respeito às especificidades dos sujeitos que compõem a EJA.

Alguns autores foram essenciais para a elaboração deste artigo. Freire (1967, 1987), contribuindo para entender os sujeitos jovens e adultos. Brandão (2002a), Fávero (2006) e Paiva (2003), no que diz respeito ao pressuposto de que há um legado da Educação Popular na história da EJA. Barcellos (1994), Cortez (2005), Fávero (1983), Góes (1991), Gullar (1965), Hollanda (1980), Rosas (1986) e Wanderley (1984), para a imersão aos movimentos de Cultura e Educação Popular da década de 1960. Streck e Esteban (2013) com a investigação do cotidiano da escola pública na perspectiva da Educação Popular.

\section{Educação e cultura popular em contextos}

\begin{abstract}
A História não repetirá os anos 60 [...]. Assim, o COMO FAZER terá que mudar. Mas, o QUE FAZER será o mesmo [...]. (GÓES, 1991, p. 10).
\end{abstract}

Revisitou-se a Educação Popular por entender que ela fundamenta a educação de jovens e adultos. Para Brandão e Assumpção (2009), educação popular diferencia-se das demais iniciativas educacionais quando emerge como um "movimento" de trabalho político com as classes populares por meio da educação.

De acordo com Streck e Esteban (2013, p. 7), uma das características fundamentais da Educação Popular é "inserir-se como instrumento pedagógico na sociedade que se movimenta em busca de dignidade, justiça e integridade da vida". Desta maneira, os lugares da educação popular não são estáticos. "Sendo visceralmente contrária a dogmati- zação, ela se reinventa em outros espaços quando instituições e grupos procuram domesticá-la." (STRECK; ESTEBAN, 2013, p. 7). Esses autores chamam atenção para a história da educação popular que continua acontecendo com novas visões e novas ferramentas. Por este motivo, o termo Educação Popular, aqui presente, não se refere a um período isolado da história, e sim às possibilidades e os desafios encontrados na atualidade, na qual grupos variados de pessoas e instituições realizam diálogos da educação com o mundo da arte, das festas populares, dos movimentos sociais, dos centros de educação e cultura popular, dentre outros lugares.

Cabe destacar que o conceito Cultura Popular, por sua vez, demandou uma escolha cuidadosa em meio a outros conceitos encontrados. Além de cultura popular, encontramos: cultura do povo; culturas populares; cultura de classe; cultura de massa; arte popular; folclore; patrimônio cultural imaterial; tradições populares; cultura tradicional; religiosidade popular e saber popular. Após avaliá-los e reconhecer que seus significados mais se aproximam do que se afastam, optouse pela permanência da "cultura popular". Dadas as convergências, a "cultura popular" é um campo de investigação consolidado que apresenta uma história e um caminho trilhado por autores/atores proeminentes no campo da educação de jovens e adultos. ${ }^{2}$

Em suas contribuições ao Dicionário Paulo Freire, Brandão (2010) afirma que cultura popular não é apenas um conceito científico herdado pelos cientistas sociais dos diferentes estudiosos das tradições populares. Para esse autor, cultura popular é "a palavra-chave de um aberto e múltiplo projeto político de transformação social a partir das próprias culturas dos trabalhadores e outros atores sociais e populares" (BRANDÃO, 2010, p. 103). Fávero (1983, p. 23), por sua

20 termo "cultura popular" é usado, entre outros, por Brandão (2002a, 2002b), Fávero (2006), Góes (1991), Paiva (2003), Wanderley (1984). 
vez, destaca que é popular a cultura quando

"é comunicável ao povo, isto é, quando suas significações, valores, ideais, obras, são destinadas efetivamente ao povo e respondem às suas exigências de realização humana em determinada época".

Cultura popular é, portanto, a manifestação do modo de ver, de pensar e de dizer daqueles que pertencem às classes populares. Brandão (2002b) afirma ainda que foi na década de 1960 que surgiu, e por algum tempo floresceu, um tipo relativamente inovador de prática pedagógica. Um trabalho "com" o povo e não "para" o povo:

Conduzido por educadores como Paulo Freire, por cientistas políticos como Carlos Estevam Martins, por políticos de carreira como Miguel Arraes, por religiosos da hierarquia católica e de seu sacerdócio mais avançado com o Pe. Henrique da Lima Vaz, o movimento dos movimentos de cultura popular era também conduzido por artistas, por poetas, como Ferreira Gullar, para quem todo o político do trabalho a fazer não devia destruir o seu sentido profundamente cultural. (BRANDÃO, 2002b, p. 68, grifo do autor).

O movimento de educação e cultura popular desenvolveu um trabalho que inseriu no nome de sua ação a palavra "cultura", diferenciando-se de outras iniciativas do tipo "povo-e-governo" então chamadas "desenvolvimento" (nacional, regional, socioeconômico, integrado), "promoção social", "organização", "educação fundamental". Como afirma Brandão (2002b, p. 37), a palavra cultura, tal como a palavra história, "a tudo amarra e dá sentido", e para Fávero (2006), os temas "cultura" e "cultura popular" se colocavam entre os mais discutidos e divulgados "nos" e "entre" os movimentos de educação e cultura popular ${ }^{3}$ do início dos anos 1960.

A cultura popular pode ser melhor apreendida quando avaliados seus conceitos-chave, que passam a ser tratados.

3 De acordo com Soares (2009), no I Encontro Nacional de Alfabetização e Cultura Popular, realizado no Recife (1963), registraram-se 78 instituições presentes.

\section{Conceitos-chave à compreensão de cultura popular}

\section{a) Cultura}

Brandão (2002b) afirma que a cultura é o mundo que criamos para aprender a viver. Macedo (1988, p. 35) reitera que "a cultura consiste num conjunto global de modos de fazer, ser, interagir e representar que, produzidos socialmente, envolvem simbolização e, por sua vez, definem o modo pelo qual a vida social se desenvolve". Comparando seu reflexo no lago com o reflexo de uma ave no galho de uma árvore, Brandão (2002b, p. 16) propõe: "eu me vejo como um ser da natureza, mas me penso como um sujeito da cultura. Como um alguém que pertence também ao mundo que a espécie humana criou para aprender a viver." Isso exige dele o que dispensa na ave, que voa, retorna ao seu ninho, como um ser que habita um absoluto presente: "requer palavras, códigos complexos de sentidos e de significados, uma linguagem articulada por meio da qual em mim e para os meus outros a sensação e o sentimento aspiram ganhar sentido" (BRANDÃO, 2002b, p. 16).

Cultura é, portanto, a interação do homem com a natureza e as relações que estabelece a partir desse contato. 0 homem, ao se diferenciar do acontecer dos outros animais, realiza cultura. Cultura essa que representa o processo e o produto do trabalho dos seres humanos no complexo acontecer da transformação de uma natureza dada. Segundo Brandão (2009, p. 719):

Culturas são panelas de barro ou de alumínio, mas também receitas de culinária e sistemas sociais indicando como as pessoas de um grupo devem proceder quando comem. São vestimentas de palha ou de pano acompanhadas de preceitos e princípios sobre modos de se vestir em diferentes situações sociais e rituais. São mapas simbólicos que guiam participantes de um mundo social entre seus espaços e momentos. Nossos corpos, atos e gestos são visíveis como expressões de nossos comportamentos. Mas o sentido do que fazemos ao agir em interações 
com nossos outros somente é compreensível mediante as culturas de que fazemos parte.

Nossos corpos são a natureza transformada nos seres que somos: pessoas. Por este motivo, afirma Laraia (1986, p. 68) que "o modo de ver o mundo, as apreciações de ordem moral e valorativa, os diferentes comportamentos sociais e mesmo as posturas corporais são assim produtos de uma herança cultural, ou seja, o resultado da operação de uma determinada cultura".

Cecília Osowski (2010, p. 98-99), quando reflete sobre o que é cultura na obra freireana, ressalta que:

Cultura para Paulo Freire é atividade humana de trabalho que transforma [...]. 0 homem como um ser de relações está no mundo e com o mundo, enfrentando os desafios que a natureza lhe coloca, precisando, inicialmente, encontrar meios para responder às suas necessidades básicas de sobrevivência. Pelo trabalho instala um processo de transformação que produz, num primeiro nível, uma cultura de subsistência que lhe permite sobreviver. Assim faz a casa, suas roupas, seus instrumentos de trabalho, criando, também modos de relacionar-se com os outros e com os processos cósmicos, com divindades e consigo mesmo.

Para Freire (1967, p. 108), a cultura é como "o acrescentamento que o homem faz ao mundo que não fez. A cultura como resultado de seu trabalho. Do seu esforço criador e recriador". Acrescenta-se ao exposto a observação feita por Chauí (1988) quanto ao uso do singular "cultura", quando, na opinião da autora, o mais correto seria o plural "culturas":

Se a cultura for considerada como uma ordem simbólica que exprime o modo pelo qual homens determinados estabelecem relações determinadas com a natureza e entre si e o modo pelo qual interpretam e representam essas relações, a pluralidade cultural permite assinalar a singularidade histórica e social de uma cultura. (CHAUÍ, 1988, p. 122-123).

Para Chauí (1988, p. 123), se mantivermos presente e viva a pluralidade, "poderemos também permanecer abertos para uma criação que é sempre múltipla, solo de qualquer proposta política que se pretenda democrática". Ainda em Laraia (1986, p. 87), lê-se que "todo sistema cultural tem a sua própria lógica e não passa de um ato primário de etnocentrismo tentar transferir a lógica de um sistema para outro". Infelizmente, porém, continua esse autor, "a tendência mais comum é de considerar lógico apenas o próprio sistema e atribuir aos demais um alto grau de irracionalismo" (LARAIA, 1986, p. 87).

\section{b) Cultura Popular}

Brandão (2002b) afirma que existe na cultura brasileira uma cultura dominante e uma cultura dominada. Refletindo condições e modos de vida de classes opostas no interior do processo produtivo, ambas configuram em uma mesma estrutura alienante de valores, símbolos e significados, expressões culturais de representação desigual do mesmo mundo dividido:

Eis porque é possível falar em: 'arte erudita' e 'arte popular', 'literatura nacional' e 'literatura de cordel', 'religião oficial' e 'religiosidade popular'. A oposição não é natural e não faz parte da essência do ser e do mundo do homem. É o resultado de uma história de divisões, de expropriações, de oposição e da consagração simbólica de tudo isso. (BRANDÃO, 2002b, p. 48 , grifo do autor).

Francisco Weffort (1988) indaga-nos como o homem do povo responde aos desafios e estrangulamentos de um desenvolvimento que o alija para as periferias, que o marginaliza de toda e qualquer participação, que lhe elimina as chances de se educar, que o torna simples produtor-produzido, sem condições de usufruir a riqueza que ele cria, e que o manipula em seus íntimos anseios, até mesmo quando se volta para o deus ou os deuses de sua vida. Nos interroga esse autor se este homem do povo resiste, mesmo relegado às margens, fazendo e refazendo aí o seu mundo. "Que sentido político e que força social representa a cultura do povo? Qual sua eficácia possível, latente ou não, no conjunto da vida social e cultural?" (WEFFORT, 1988, p. 10). 
É nesse sentido, portanto, que observamos em Paulo Freire (1987) todo seu esforço em apresentar um tensionamento entre oprimidos e opressores. Os primeiros, economicamente explorados, politicamente dominados e culturalmente marginalizados, e os segundos, aqueles que exploram, dominam e marginalizam. No prefácio do livro Pedagogia do Oprimido (FREIRE, 1987), Ernani Fiori (1987, p. 10) introduz o pensamento de Freire relacionando cultura e alfabetização, na medida em que "a alfabetização não é um jogo de palavras, é a consciência reflexiva da cultura, a reconstrução crítica do mundo humano, a abertura de novos caminhos, o projeto histórico de um mundo comum, a bravura de dizer a sua palavra". Freire (1987, p. 17, grifo do autor), assim, justifica o referido livro:

Pedagogia do Oprimido: aquela que tem de ser forjada com ele e não para ele, enquanto homens ou povos, na luta incessante de recuperação de sua humanidade. Pedagogia que faça da opressão e de suas causas objeto da reflexão dos oprimidos, de que resultará o seu engajamento necessário na luta por sua libertação, em que esta pedagogia se fará e refará.

É dessa maneira que utilizamos sua frase: "ninguém liberta ninguém, ninguém se liberta sozinho: os homens se libertam em comunhão" (FREIRE, 1987, p. 29), para adentrar na necessária "ação cultural para a liberdade", que em obra homônima, o autor se debruça:

Ação cultural como a entendemos não pode, de um lado, sobrepor-se à visão do mundo dos camponeses e invadi-los culturalmente; de outro, adaptar-se a ela. Pelo contrário, a tarefa que ela coloca ao educador é a de, partindo daquela visão, tomada como um problema, exercer, com os camponeses, uma volta crítica sobre ela, de que resulte sua inserção, cada vez mais lúcida, na realidade em transformação. (FREIRE, 1982, p. 36).

A ação que os anos 1960 viram surgir foi "uma ampla e nunca unitária crítica de teor ideológico dirigida à educação vigente, [...] uma também ampla, difusa - e, não raro, confusa - proposta nacional de 'cultura popular'”
(BRANDÃO, 2002a, p. 146, grifo do autor).

Segundo Brandão (2002b, p. 51, grifo do autor), aos olhos dos anos 1960, a cultura popular era a maneira através da qual a cultura do povo, subalterna, pertencente às classes populares, poderia se tornar instrumento de luta política e revolucionária, pois "este é o processo pelo qual as palavras 'cultura' e 'popular' passam do significar as 'tradições do povo', ao traduzir o 'movimento das classes populares'". Percebemos, assim, o sentido de luta da cultura popular, contra uma cultura alienada, dominante, de um adversário que reúne o seu poder na imposição de uma cultura erudita, opressora. 0 autor acrescenta que "também o meio pelo qual a ideia de cultura ganha o sentido de instrumento popular de conscientização, de politização e de organização de classe" (BRANDÃO, 2002b, p. 51).

Fundada em ideologias diversas e associada a "frentes de luta", movimentos entre reformadores e revolucionários, "cultura popular" surgiu como um corpo de ideias e de práticas questionadoras e renovadoras (BRANDÃO, 2009). Cultura popular significa, portanto, "uma múltipla e diferenciada - mas não desigualada e desigualadora - experiência de criação cultural [...], através de um trabalho que afirmasse a liberdade, negando a possibilidade de domínio de grupos e classes sociais uns sobre os outros" (BRANDÃO, 2009, p. 732).

Nas palavras de Octavio Ianni (1988, p. 136),

As festas juninas, que no meio rural são muito importantes, não são simplesmente uma manifestação da religiosidade popular, ou do catolicismo rural, mas são muito mais do que isto. São festas religiosas e profanas que inclusive dizem respeito ao ciclo sazonal das atividades agrícolas. Nas festas juninas rurais há danças, bailes, cantos, jogos [...]. É provável que haja nas festas juninas uma manifestação autêntica de povo, no sentido de uma população rural que produziu, ao longo do tempo, assimilando inclusive influências portuguesas, toda uma sabedoria das coisas, toda uma maneira de explicar o seu relacionamento entre si, com a natureza, com deus e com o diabo. Além disso, ainda no nível do rural, há um mundo de contos, histórias e 
causos, dos vários tipos, relatos e fantasias, que expressam uma tremenda riqueza na maneira de ver, de pensar, de articular o que é o universo social, cultural, natural etc., dessa gente.

Sendo assim, o termo "cultura popular" refere-se às riquezas das expressões da vida de quem é popular e ao movimento de libertação que estas práticas proporcionam. É possível identificar a amplitude da cultura popular nos próprios movimentos desenvolvidos em meados dos anos de 1960 pelo Brasil. Para tanto, destacam-se quatro proeminentes movimentos, de acordo com Fávero (2006), para aprofundamento do ideário da educação e cultura popular.

\section{Os movimentos de educação e cultura popular}

Agora, o senhor chega e diz que até podia ser diferente, não é assim? [...]

Então que podia ser um tipo de educação

até fora da escola, sala.

Que fosse assim dum jeito misturado com o-detodo-dia da vida da gente daqui.

Que podia ser um modo desses de juntar saber com saber e clarear os assunto que a gente sente, mas não sabe. Isso? (SOUSA, 1980, p. 197).

Os movimentos ligados à promoção da cultura popular, como indica Paiva (2003), nasceram das preocupações dos intelectuais, políticos e estudantes com a participação política das massas em meio ao processo de tomada de consciência da problemática brasileira que caracterizou os últimos anos do governo Juscelino Kubitschek (1956-1961). Fortemente influídos pelo nacionalismo, pretendiam o rompimento dos laços de dependência com o exterior e sua cultura de elite, buscando a valorização da cultura autenticamente nacional - a cultura do povo - e seu instrumento fundamental - a educação.

Os diversos grupos lançam-se ao campo da atuação educativa com objetivos políticos claros e mesmo convergentes, embora cada um deles enfocasse o problema à sua maneira e mesmo lutassem entre si. Pretendiam todos a trans- formação das estruturas sociais, econômicas e políticas do país, sua recomposição fora dos supostos da ordem vigente; buscavam criar a oportunidade de construção de uma sociedade mais justa e mais humana. (PAIVA, 2003, p. 258).

Reconhecer as especificidades dos movimentos de educação e cultura popular é evidenciar o que é próprio deste campo, explicitando suas necessidades. Trata-se de realizar o levantamento de peculiaridades e particularidades dos movimentos e extrair a convergência de aspectos que permitiram a eles agirem de modo próprio, produzindo algo peculiar, particular.

A efervescência de movimentos populares que marcaram a história do Brasil na década de 1960 exige que seja feito um recorte levando em conta os mais expressivos. Segundo Góes (1991), o surgimento no Brasil de movimentos semelhantes é tão intenso que, em setembro de 1963, no Recife, já se reuniam muitas organizações de alfabetização e cultura popular.

Para que seja possível realizar o aprofundamento aqui proposto, optou-se por quatro movimentos gestados no início dos anos de 1960 e interrompidos em 1964 com o golpe civil-militar: ${ }^{4}$ a) Movimento de Cultura Popular, criado em maio de 1960, sob o patrocínio da Prefeitura do Recife, como sociedade civil autônoma; b) Campanha de Pé no Chão Também se Aprende a Ler, deflagrada em Natal, em 23 de fevereiro de 1961, pela Secretaria de Educação de Natal; c) Movimento de Educação de Base, lançado pela Conferência Nacional dos Bispos do Brasil, em convênio com o Governo Federal, em março de 1961; d) Centro Popular de Cultura, criado pela União Nacional dos Estudantes, em abril de 1961.

A reflexão aqui proposta alimenta-se das contribuições desses quatro movimentos, destaca os programas desenvolvidos no interior de cada um deles e analisa como a cultura fez parte de suas prioridades como um "princípio" e não um "fim" dos processos educativos. Portanto, busca-se aqui analisar como a educação

4 Exceto o Movimento de Educação de Base (MEB), que se reinventou durante o período militar. Sobre o assunto, conferir Fávero (2006). 
popular e a cultura popular podem continuar sendo um caminho fecundo para a formação dos estudantes como partes importantes de um currículo que se propõe a trabalhar com Educação de Jovens e Adultos.

Busca-se evidenciar o que é próprio da educação e cultura popular, através de quatro pontos: a) Conceitos assumidos; b) Objetivos a alcançar; c) Planos de Ação.

\section{a) Conceitos assumidos}

Destaca-se, a partir dos estudos de Osmar Fávero, ${ }^{5}$ os conceitos fundamentais de cultura popular introduzidos pelos movimentos, bem como outros termos a eles vinculados, que se constituíram em suas bases comuns ao serem incorporados nas propostas de ação. Fávero (1983) se vale dos documentos orientadores dos movimentos para tratar dos conceitos assumidos.

Em Fávero (1983, p. 60-61) encontra-se que o CPC parte do entendimento de que a arte é capaz de converter-se em força ativa eficiente e teria potencial para incidir na sociedade, pois, "tal fato constitui, precisamente, a própria condição de possibilidade de toda e qualquer arte revolucionária e é dela que o CPC extrai a razão de ser e o fundamento primeiro de sua existência como entidade artística e cultural de caráter popular e revolucionário".

Já o movimento de Pé no Chão Também se Aprende a Ler, em tentativa de conceituação, agrega a cultura popular em duas fases. A primeira afirma que a luta interna de libertação está ligada ao sentido de desalienação da própria cultura. Em um segundo momento, seguindo com Fávero (1983, p. 74), “um caráter de luta, que, ao lado da formação de uma autêntica cultura nacional, promove a

5 Dirigente do MEB nos anos de 1960, Professor Emérito da Universidade Federal Fluminense (UFF), documentalista e coordenador do Núcleo de Estudos e Documentação sobre Educação de Jovens e Adultos (NEDEJA/UFF). Osmar Fávero organizou um acervo digital de educação popular que inclui fontes documentais, relatórios, depoimentos, entrevistas, livros, artigos, e, especialmente, o material didático (cartilhas, livros de leitura, vídeos, fotos, slides, folhetos de cordel, entre outros) que é referência nos estudos de educação e cultura popular. integração do homem brasileiro no processo de libertação econômico-social e políticocultural do nosso povo". De posse da cultura popular, o homem transcende a recepção passiva e passa a ser criador de diferentes manifestações culturais.

O MEB apresenta a cultura popular em seu documento Notas para estudo, colocando-a como um fenômeno surgido em sociedades que apresentam desnível cultural onde faz-se necessário ação efetiva de organizações de cultura popular. Tais organizações são assim chamadas, de acordo com Fávero (1983, p. 77-78, grifo do autor), "não porque sejam os 'sujeitos de uma cultura autêntica do povo', nem porque levam 'o folclore ao povo', mas porque pretendem agir no sentido da superação, pela sociedade, dos desníveis entre os diversos grupos sociais que a compõem".

O Plano de Ação para 1963 do Movimento de Cultura Popular, afirma, ainda com Fávero (1983, p. 91), que ele "não gera um movimento cultural qualquer" e, sim, "um movimento de cultura popular". Significa que, do ponto de vista cultural, os interesses do movimento popular têm, portanto, um caráter específico: "exprimem a necessidade de uma produção cultural, a um só tempo, voltada para as massas e destinada a elevar o nível de consciência social das forças que integram, ou podem vir a integrar, o movimento popular."

\section{b) Objetivos a alcançar}

Os objetivos são tratados como instrumentos de trabalho que, junto com os valores que cada movimento adotou, se definem a partir das necessidades da comunidade à qual se destinam, tendo a cultura popular como ponto em comum. De acordo com o Estatuto do MCP, Cap. I, Art. 1:: "Sob a denominação de Movimento de Cultura Popular fica fundada e constituída uma sociedade civil, brasileira, de finalidade educativa e cultural" (MOVIMENTO..., 1986, p. 57). Registrado em 1961, no Cartório do $2^{\text {o }}$ Ofício de Recife, Pernambuco, o documento dispõe os seguintes objetivos: 
1- Promover e incentivar, com a ajuda de particulares e dos poderes públicos, a educação de crianças e adultos; 2- Atender ao objetivo fundamental da educação que é o de desenvolver plenamente todas as virtualidades do ser humano, através de educação integral de base comunitária, que assegure, também, de acordo com a Constituição, o ensino religioso facultativo; 3- Proporcionar a elevação do nível cultural do povo preparando-o para a vida e para o trabalho; 4- Colaborar para a melhoria do nível material do povo através de educação especializada; 5- Formar quadros destinados a interpretar, sistematizar e transmitir os múltiplos aspectos da cultura popular. (MOVIMENTO..., 1986, p. 57).

Paulo Rosas (1986, p. 29) destaca o sentido de mudança da ordem vigente nos objetivos do MCP, através da cultura e da educação:

Como se vê, seus objetivos eram fundamentalmente educativos. Pensava-se que, através da educação, toda uma camada social e injustamente alijada do processo de desenvolvimento social e humano, sem acesso ao sistema de informação e crescimento de seus indivíduos, a não ser de modo bissexto e com o sacrifício de seus valores culturais, pudesse forçar a mudança no sistema econômico e vigente e conquistar aquilo a que tinha direito. Pensava-se que tal objetivo jamais seria alcançado através dos modelos convencionais de educação formal. A educação popular, esperava-se, seria o caminho a seguir.

De forma semelhante, a Campanha de Pé no Chão Também se Aprende a Ler, iniciada em 23 de fevereiro de 1961, pelo então Prefeito de Natal, Djalma Maranhão, centrou-se na educação popular. Segundo Cortez (2005, p. 19), o “objetivo era promover a alfabetização, não apenas das crianças em idade escolar, mas também de jovens e adultos". Nas palavras da autora, a Campanha tinha "2.974 alunos matriculados em escolinhas que funcionavam em locais cedidos pela comunidade local como igrejas, sindicatos e casa oferecida voluntariamente pelo proprietário" (CORTEZ, 2005, p. 19).

Góes (1991) relata o quadro de analfabetismo da época, afirmando a urgência e a necessidade da explosão de movimentos como a Campanha de Pé no Chão Também se Aprende a Ler, pois, tratando-se do índice de analfabe- tismo na população acima de 14 anos, "o mais alto era o Nordeste $(59,97 \%)$ e, em Natal, o Censo de 1960 revelara a existência de 60.254 analfabetos, cifra possível de ser decomposta em 35.810 crianças e 24.444 adultos" (GÓES, 1991, p. 69).

Neste sentido, Cortez (2005, p. 215) afirma que

A Campanha tinha como prioridade absoluta a alfabetização de todas as crianças em idade escolar e de todos os adultos não alfabetizados, cuja oportunidade para aquisição das letras lhes havia sido negada. Para atingir tal prioridade era necessário preparar pessoal, isto é, qualificar pessoas para exercerem a tarefa de difundir o conhecimento, capazes de ler não apenas a palavra, mas ler o mundo e interpretar a realidade, e não somente isso, mas exercer sobre ela uma crítica reflexiva.

Se o MCP e a Campanha de Pé no Chão preocupavam-se com a educação e cultura popular, os primeiros documentos do MEB, elaborados no início de 1961, indicavam como seu objetivo de "ministrar educação de base às populações das áreas subdesenvolvidas do Norte, Nordeste e Centro-Oeste do país, através de programas radiofônicos especiais com recepção organizada" (MEB, 1965, p. 19 apud FÁVERO 2006, p. 56) seria executado.

Fávero (2006, p. 4) acrescenta uma característica importante do Movimento de Educação de Base:

De todas as experiências citadas, o MEB foi a única que logrou intensa penetração no meio rural, inclusive dando apoio decisivo à sindicalização rural, principalmente no início dos anos de 1960. E foi o único movimento que sobreviveu ao golpe militar de 1964 e à repressão dos anos seguintes, devido exclusivamente ao fato de ser um movimento da Igreja.

Sob o manto da igreja, o MEB reestruturou as estratégias de ação visando realizar os seguintes objetivos:

a) executar naquelas áreas um programa intensivo de alfabetização, educação cívica, educação sanitária, iniciação profissional, sobretudo agrícola, promoção social; b) suscitar, em torno de cada escola radiofônica, a organização da comu- 
nidade, despertando-lhe o espírito de iniciativa e preparando-a para as indispensáveis reformas de base, como a da estrutura agrária do país; c) velar pelo desenvolvimento espiritual do povo, preparando-o para o indispensável soerguimento econômico das regiões subdesenvolvidas e ajudando-o a defender-se de ideologias incompatíveis com o espírito cristão da nacionalidade. (MEB, 1965, p. 23 apud FÁVERO, 2006, p. 56).

Vale relembrar que o MEB iniciou suas atividades de educação pelo rádio nas arquidioceses de Natal e Aracajú, quando a Conferência Nacional dos Bispos do Brasil (CNBB) elaborou um plano nacional, mediante o qual o Governo Federal forneceria os recursos necessários (WANDERLEY, 1984). Sobre os motivos que teriam levado o governo a aceitar a proposta da Igreja, observam-se várias interpretações:

Uma primeira giraria em torno da estratégia típica da política populista, visando fortalecer o novo governo que não dispunha de uma máquina eleitoral própria - ou seja, ampliar o contingente eleitoral. Uma segunda suporia o já mencionado cuidado particular com o setor de educação, acrescido do desejo de responder a apelos da UNESCO para campanhas de alfabetização e a apelos de educadores nacionais. A terceira procura restringir o poder político das oligarquias rurais. [...] E a quarta, também dentro da estratégia populista, suporia a intenção de controlar ideológica e organizacionalmente as massas rurais, que estavam sob o assédio de grupos de esquerda e que tentavam mobilizar e organizar o campo. (WANDERLEY, 1984, p. 49).

Entretanto, esse autor destaca que havia por parte da Igreja Católica a tradicional preocupação com a área da educação e com trabalhos de ação social e promoção humana de populações desassistidas que não podem deixar de ser considerados quando se analisa a ação do MEB

Os objetivos do CPC da UNE estão presentes no documento Anteprojeto do Manifesto do Centro Popular de Cultura, redigido em março de 1962, que discorre sobre a "Arte Popular Revolucionária":

0 CPC não poderia nascer, nem se desenvolver e se expandir por todo o país senão como momento de um árduo processo de ascensão das massas. Como órgão cultural do povo, não poderia surgir antes mesmo que o próprio povo tivesse se constituído em personagem histórico, não poderia preceder o movimento fundador $\mathrm{e}$ organizativo pelo qual as massas se preparam para a conquista de seus objetivos sociais. (HOLLANDA, 1980, p. 127).

Hollanda (1980) extraiu do referido documento a posição assumida pelos membros do CPC: "considerando as 'próprias perspectivas revolucionárias' que se apresentam ao 'homem brasileiro', o Manifesto postula o engajamento do artista e afirma que 'em nosso país e em nossa época, fora da arte política não há arte popular'” (HOLLANDA, 1980, p. 17).

Gullar (1965, p. 4) afirma que "pode-se perceber como se coloca para o poeta, como para o autor teatral, para o cineasta, como para o novelista, o problema da criação artística, no âmbito da cultura popular", e complementa,

Nesse ponto, deve-se acentuar a importância que tem desempenhado, na vida cultural brasileira, o movimento universitário, cujo centro de irradiação é a União Nacional dos Estudantes. 0 papel da UNE se realiza, não só através do impulso que dá aos Centros Populares de Cultura, que hoje se multiplicam pelo país inteiro, mas também através dos seminários que organiza, das publicações e das campanhas públicas de esclarecimento do homem da rua e da própria massa estudantil. (GULLAR, 1965, p. 6).

De modo geral, os movimentos destacam o papel do escritor, do cineasta, do pintor, do professor, do estudante, do profissional liberal etc. como cidadãos diretamente responsáveis, como os demais trabalhadores, pela sociedade que ajudam a construir diariamente.

\section{c) Planos de ação}

O alcance dos movimentos de educação e cultura popular pode ser melhor apreendido quando se observam os planos de ação alinhados aos conceitos assumidos e aos objetivos traçados.

No documento MCP/Plano de Ação para 1963, item 4, são anunciados dois meios para a concretização das ações do movimento: um voltado para dentro e outro voltado para fora. 
Os meios voltados para fora subdividem-se em meios diretos e indiretos:

1. Meios diretos: a) desenvolver atividades formativas incidentes sobre os seguintes níveis da experiência humana, intelectual, profissional, político, artístico, social, recreativo, esportivo e organizativo; b) desenvolver atividades informativas que interessem e motivem a comunidade nas atividades desenvolvidas pelo movimento. 2. Meios indiretos: a) criar, nas organizações integrantes do movimento popular, núcleos de cultura popular constituídos e ativados pelos próprios membros dessas organizações; b) desenvolver atividades capazes de articular aspirações culturais não organizadas que estão na origem de futuros grupos de ação cultural popular; c) assessorar técnica, cultural e materialmente os núcleos culturais populares autodirigidos; d) elevar cada atividade à condição de campanha, criando para tanto os incentivos necessários a que as forças populares assumam como suas iniciativas particulares originalmente no interior do movimento; e) aprofundar o caráter popular das campanhas de iniciativa governamental; f) generalizar, para todos, as iniciativas partidas de um ou poucos grupos populares. (MOVIMENTO..., 1986, p. 54-55).

Rosas (1986, p. 30-31) indicou algumas ações significativas do movimento que, com menos de três anos em atividade, acumulou:

201 escolas, com 626 turmas; 19.646 alunos, entre crianças, adolescentes e adultos; uma rede de escolas radiofônicas; um centro de artes plásticas e artesanato, com cursos de tapeçaria, tecelagem, cerâmica, cestaria, cartonagem, fantoches, pintura, desenho, estamparia, modelagem, gravura e escultura (destinado principalmente a especializar o professorado do próprio MCP); 452 professoras e 174 monitores, ministrando o ensino correspondente ao primeiro grau, supletivo, educação de base e educação artística; uma escola para motoristas-mecânicos; cinco praças de cultura; as praças em tela levavam ao povo local biblioteca, teatro, cinema, tele-clube, música, orientação pedagógica, jogos infantis, educação física; Centro de Cultura Dona Olegarinha, no Poço da Panela, em colaboração com a Paróquia de Casa Forte, com tele-clube, cursos de corte e costura, alfabetização e educação de base; círculos de cultura; galeria de arte; conjunto teatral, tendo encenado as seguintes peças: 'Chapeuzinho Vermelho', de Paulo Magalhães; 'Um menino nos foi dado', de Dom Marcos Barbosa; 'A derradeira ceia', de Luiz Marinho; 'Julgamento em Novo Sol', de Nelson Xavier, Boal, Trevisan, Caruso e Benedito Araújo; e a 'Volta do Camaleão Alface', de Maria Clara Machado.

A experiência da Campanha de Pé no Chão Também se Aprende a Ler é descrita por Góes (1991) em oito fases: As Escolinhas; Os Acampamentos Escolares; O Ensino Mútuo; As Praças de Cultura; O Centro de Formação de Professores; A Campanha De Pé no Chão Também se Aprende uma Profissão; A interiorização da Campanha e A escola brasileira construída com dinheiro brasileiro.

Dentre os Programas Culturais disponibilizados pelo autor, destacamos: Folclore/Museu/ Arte Popular C. Cascudo; I Seminário Educação Cultura Município de Natal (1961); Praça de Cultura (Parque infantil/Quadra esportiva/ Biblioteca/Concha Acústica/Galeria de Arte/ Debates/Radio-difusão/Cinema/TV) e I Congresso de Cultura Popular / Teatrinho do povo (1963) (GÓES, 1991).

Fávero (2006, p. 9) expõe as ações do MEB, afirmando, primeiramente, a hipótese de que "pelo compromisso assumido com o povo e pela dimensão política decorrente desse compromisso, a prática educativa do MEB converteu-se numa original pedagogia da participação popular". São elas: Sistema radioeducativo; Material didático; Animação popular e Formação de quadros.

As escolas radiofônicas do MEB foram, na sua primeira fase, o instrumento básico de ação, pois havia no país "escolas radiofônicas atendendo à escolarização da população jovem e adulta, desenvolvendo um conteúdo de alfabetização (leitura, escrita e cálculo) ao qual se somavam alguns conhecimentos de saúde, de agricultura, de vida associativa, de religião" (FÁVERO, 2006, p. 130). 0 material didático foi uma preocupação de se elaborar conteúdo específico para os adolescentes e adultos diferenciando-os do tratamento dado 
às crianças. No caso do MEB, a elaboração de material próprio acontece após o 1ํㅡㄹ Encontro Nacional de Coordenadores, em 1962. Por fim, o essencial da animação popular era a mobilização e a organização das camadas populares por meio do plano de ação em torno da conscientização e da politização, visando transitar da consciência individual para a consciência de classe.

No item que corresponde às atividades realizadas e em desenvolvimento do Relatório do CPC, são apresentadas:

a) Atuação para os grupos sociais: Campanha pela Reforma Universitária; UNE Volante; Esclarecimento popular (setembro-outubro de 1962); Mobilização da intelectualidade. b) Atuação com os grupos sociais: A UNE tem dois instrumentos de ação de cultura popular: O CPC e a Campanha de Alfabetização, organismos estes que, embora autônomos, trabalham intimamente vinculados. [...] Teatro; Seminário de Dramaturgia; Cursos; Livros; Cordel - Folhetos de feira; Reportagem; Televisão; Rádio; Imprensa; Música; Discos; Cinema; Divulgação e propaganda. (BARCELLOS, 1994, p. 441-456).

Ainda segundo o relatório do CPC, a atuação com os grupos sociais é considerada a essência do movimento, pois "é o povo mobilizado em suas vanguardas, criando seu núcleo, aprendendo e ensinando a tornar ação social, a tornar concretos seus conhecimentos do mundo pela prática transformadora" (BARCELLOS, 1994, p. 446). O documento dispõe ainda sobre algumas ações do CPC como a Campanha pela Reforma Universitária, a UNE Volante, o Esclarecimento popular e a Mobilização da intelectualidade.

As especificidades dos movimentos de educação e cultura popular detalhados acima nos mostram que assumir uma relação entre educação e cultura popular torna-se instrumento quando o assunto é democratizar os meios de ascensão dos grupos populares. Seus conceitos, objetivos e planos de ação demonstram os caminhos almejados para que os atores sociais, homens e mulheres do povo, tornem-se responsáveis pela própria libertação.

\section{Considerações finais}

[...] descruza os braços, renuncia a ser simples espectador e exige participação.

Já não se satisfaz em assistir; quer participar; quer decidir. (FREIRE, 1979, p. 38).

Quando andamos, andamos com a nossa cultura. Ao entrar na discussão em torno da bagagem cultural que cada pessoa carrega ao longo da vida e analisá-la à luz dos movimentos de educação e cultura popular desenvolvidos nos primeiros anos de 1960, nota-se que ela não pode ficar de fora da educação nem dos debates a respeito da participação de jovens e adultos no próprio processo educativo, como sugere Paulo Freire. Reconhecer a cultura do outro é também democratizar a educação. A inserção da cultura popular no interior de propostas pedagógicas promove valorização e respeito a toda experiência social. Tal inserção esteve presente nos movimentos de educação e cultura popular como o MCP, CPC, MEB e a Campanha de Pé no Chão. O conjunto de ações propostas por eles com base na cultura popular leva-nos a concluir que educação popular diz respeito a reconhecer princípios, concepções, fundamentos e valores advindos do pressuposto de que a educação pode ser construída por meio do diálogo e da valorização da cultura popular, aliados às dimensões política e à promoção da emancipação dos homens e das mulheres.

Nos objetivos dos movimentos de educação e cultura apreende-se que não é possível um trabalho de cultura popular desligado do processo de conscientização. Por este motivo Brandão (2009) afirma que as propostas dos movimentos de educação popular dos anos 1960 redimensionam o valor original da cultura popular. Neles há experiências diferenciadas que negam "a possibilidade de domínio de grupos e classes sociais uns sobre os outros" (BRANDÃO, 2009, p. 732).

Pode-se perceber com Esteban e Tavares (2013, p. 299, grifo do autor) que nos "interstícios da história oficial, nos diferentes 
cotidianos que se constroem à margem das práticas hegemônicas e uniformizantes, longe do controle e da regulamentação da inclusão degradada, desenham-se projetos escolares potentes e afirmativos". Para esses autores, seria uma forma de negar o que comumente a escola pública tem sido: uma escola pobre para os pobres. 0 fato de direcionar o olhar para a educação e cultura popular desenvolvida nos anos de 1960 muito se deve às raízes que $a$ educação de jovens e adultos tem nesse campo. Partindo desse pressuposto, muitas práticas atuais em EJA chegam a confundir "eventos culturais" e "eventos de cultura popular". Pelo acima exposto, algumas palavras de ordem são importantes para caracterizar o segundo evento, como "conscientização", "libertação", "politização" que não necessariamente estão presentes nos eventos culturais

Cabe ressaltar que ainda é chegada a hora de fazer com que as culturas ditas também subalternas, oprimidas, alienadas ou dominadas não apenas falem de si e de seus mundos, mas, sim, utilizem de seus contos e cantos para dizer algo de modo crítico a respeito de sua condição social e transponham para um plano político "aquilo que até então havia sido estudado e compreendido como apenas residualmente 'cultural'" (BRANDÃO, 2009, p. 731, grifo do autor). A lição que os movimentos de educação e cultura popular deixam é que todo trabalho assumidamente cultural e de luta política não aconteceu de forma isolada. Envolveu pessoas e grupos, como políticos, artistas, militantes cristãos, intelectuais, estudantes universitários, juntos com o povo. Afinal, os objetivos dos movimentos centram a cultura e a educação popular no cerne da ação de modo a permitir a participação dos homens e das mulheres.

Uma educação não mais pensada "para" as pessoas, mas "com" as pessoas. "Com" os sujeitos participantes e construtores de uma realidade na qual se reconhecem. Sabemos que alguns caminhos já estão sendo trilhados em várias iniciativas, através de debates entre educadores, gestores e educandos; documen- tos que abordam a cultura; investimentos em visitas a espaços externos à escola, festas juninas, mostras culturais e atividades diversas, como grupos de dança, oficinas de contação de história, grupos de teatro, palco, luz, "respeitável público", são exemplos preciosos de ver a cultura associando-se com a educação.

\section{REFERÊNCIAS}

BARCELLOS, Jalusa. CPC da UNE: uma história de paixão e consciência. Rio de Janeiro: Nova Fronteira, 1994.

BRANDÃO, Carlos Rodrigues. A educação popular na escola cidadã. Petrópolis, RJ: Vozes, 2002a.

BRANDÃO, Carlos Rodrigues. A educação como cultura. Campinas, SP: Mercado de Letras, 2002b.

BRANDÃO, Carlos Rodrigues. Vocação de criar: anotações sobre a cultura e as culturas populares. Cadernos de Pesquisa, v. 39, n. 138, p. 715-746, set./dez. 2009.

BRANDÃO, Carlos Rodrigues. Cultura popular. In: STRECK, D. R.; REDIN, E.; ZITKOSKI, J. J. (org.). Dicionário Paulo Freire. 2. ed. rev. e ampl. Belo Horizonte: Autêntica, 2010. p. 103-107.

BRANDÃO, Carlos Rodrigues; ASSUMPÇÃO, Raiane. Cultura rebelde: escritos sobre a educação popular ontem e agora. São Paulo: Editora e Livraria Instituto Paulo Freire, 2009.

CHAUÍ, Marilena. Cultura do povo e autoritarismo das elites (texto-base). In: VALLE, Edênio; QUEIROZ, José J. (org.). A cultura do povo. 4. ed. São Paulo: Cortez/Instituto de Estudos Especiais, 1988. p. 119-134.

CORTEZ, Margarida J. Memórias da Campanha "De Pé no Chão Também se Aprende a Ler": reflexões sobre a prática pedagógica de ontem e de hoje. Natal: Editora da UFRN, 2005.

ESTEBAN, Maria T.; TAVARES, Maria T. G. Educação popular e a escola pública: antigas questões e novos horizontes. In: STRECK, D. R.; ESTEBAN, M. T. (org.). Educação Popular, lugar de construção coletiva. Petrópolis, RJ: Vozes, 2013. p. 293-307.

FÁVERO, Osmar (org.). Cultura popular e educação popular: memória dos anos 60 . Rio de Janeiro: Graal, 1983.

FÁVERO, Osmar. Uma pedagogia da participação popular: análise da prática educativa do MEB - 
Movimento de Educação de Base (1961/1966). Campinas, SP: Autores Associados, 2006.

FIORI, Ernani Maria. Aprender a dizer a sua palavra. In: FREIRE, Paulo. Pedagogia do oprimido. 17. ed. Rio de Janeiro: Paz e Terra, 1987. p. 05-11.

FREIRE, Paulo. Educação como prática da liberdade. 1. ed. Rio de Janeiro: Paz e Terra, 1967.

FREIRE, Paulo. Educação e mudança. Rio de Janeiro: Paz e Terra, 1979.

FREIRE, Paulo. Ação Cultural para a liberdade e outros escritos. 6. ed. Rio de Janeiro: Paz e Terra, 1982.

FREIRE, Paulo. Pedagogia do oprimido. 17. ed. Rio de Janeiro: Paz e Terra, 1987.

FREIRE, Paulo. Paulo Freire. In: SILVESTRE, Edney. Contestadores: entrevistas notáveis. São Paulo: Francis, 2003.

GÓES, Moacyr de. De pé no chão também se aprende a ler, 1961-1964: uma escola democrática. 2. ed. São Paulo: Cortez, 1991.

GULLAR, Ferreira. Cultura posta em questão. Rio de Janeiro: Civilização Brasileira S.A., 1965.

HOLLANDA, Heloísa Buarque de. Impressões de viagem: CPC, vanguarda e deslumbre - 1960/1970. São Paulo: Brasiliense, 1980.

IANNI, Octavio. Cultura do povo e autoritarismo das elites (texto-comentário). In: VALLE, Edênio; QUEIRÓZ, José J. (org.). A cultura do povo. 4. ed. São Paulo: Cortez/Instituto de Estudos Especiais, 1988. p. 134-140.

LARAIA, Roque de Barros. Cultura: um conceito antropológico. Rio de Janeiro: Zahar, 1986.

MACEDO, Carmen Cinira. Algumas observações sobre a questão da cultura do povo. In: VALLE, Edênio; QUEIRÓZ, José J. (org.). A cultura do povo. 4. ed. São Paulo: Cortez/Instituto de Estudos Especiais, 1988. p. 34-39.

MOVIMENTO da Cultura Popular: Memorial MCP 26 anos. Recife: Movimento de Cultura Popular/ Fundação de Cultura Cidade do Recife, 1986.

OSOWSKI, Cecília Irene. Cultura. In: STRECK, D. R.;
REDIN, E.; ZITKOSKI, J. J. (org.). Dicionário Paulo Freire. 2. ed. rev. e ampl. Belo Horizonte: Autêntica, 2010.

PAIVA, Vanilda. História da educação popular no Brasil: educação popular e educação de adultos. 6 . ed. rev. e ampl. São Paulo: Loyola, 2003.

PINHO, Clarice Wilken. Educação e cultura popular nas propostas escolares de EJA - Educação de Jovens e Adultos: um estudo em duas escolas de Belo Horizonte. 2016. 166f. Dissertação (Mestrado em Educação) - Faculdade de Educação, Universidade Federal de Minas Gerais (UFMG), Belo Horizonte, 2016.

ROSAS, Paulo. O Movimento de Cultura Popular - MCP. In: Movimento da Cultura Popular: Memorial MCP 26 anos. Recife: Movimento de Cultura Popular/Fundação de Cultura Cidade do Recife, 1986. p. 19-36.

SOARES, Leôncio J. G. O I Encontro Nacional de Alfabetização e Cultura Popular. In: SOARES, Leôncio J.G.; FÁVERO, Osmar (org.). I Encontro Nacional de Alfabetização e Cultura Popular. Brasília, DF: MEC/UNESCO, 2009. p. 15-30.

SOUSA, Antônio Cícero. Posfácio. In: BRANDÃo, Carlos R.; BEZERRA, Aída (org.). A questão política da educação popular. 2. ed. São Paulo: Brasiliense, 1980. p. 197-198.

STRECK, D. R.; ESTEBAN, M. T. (org.). Educação Popular, lugar de construção coletiva. Petrópolis, RJ: Vozes, 2013.

WANDERLEY, Luiz E. W. Educar para transformar: educação popular, Igreja Católica e política no Movimento de Educação de Base. Petrópolis, RJ: Vozes, 1984.

WEFFORT, Francisco C. Nordestinos em São Paulo: notas para um estudo sobre cultura nacional e cultura popular. In: VALLE, Edênio; QUEIRÓZ, José J. (org.). A cultura do povo. 4. ed. São Paulo: Cortez/ Instituto de Estudos Especiais, 1988. p. 13-23.

Recebido em: 15/11/2019

Revisado em: 24/05/2020

Aprovado em: 08/08/2020

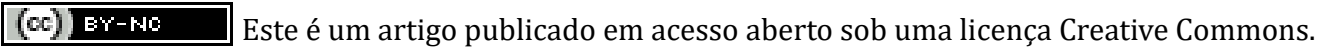

